\title{
A leitura de poesia e sua escolarização: os livros didáticos e a formação de leitores
}

\author{
Poetry Reading and schooling: textbooks and the education of readers
}

\author{
Caroline Dambrozio Guerra \\ Marcus de Martini \\ Universidade Federal de Santa Maria - UFSM - Santa Maria - Rio Grande do Sul - Brasil
}

\begin{abstract}
Resumo: Este artigo apresenta uma análise da abordagem à poesia presente no livro Português contemporâneo: diálogo, reflexão e uso (2017), o livro didático mais escolhido e, consequentemente, mais distribuído a partir do Programa Nacional do Livro e do Material Didático (PNLD) de 2018. Objetivando refletir sobre o lugar ocupado pelo letramento lírico nas salas de aula brasileiras, este texto discute as problemáticas que envolvem os estudos dos gêneros literários (principalmente 0 "lírico"), dos livros didáticos e da formação de leitores. O panorama parcial apresentado não é novo: segue-se, na escola, uma tradição já consolidada na abordagem didática de poesia. Embora seja possível perceber, cada vez mais, um avanço teórico quanto aos temas, esse avanço restringe-se ao espaço acadêmico, não alcançando lugar na escola. Além disso, se os pressupostos teóricos chegam à escola, o que ocorre é uma "colagem" de conceitos e sistematizações que não auxiliam no contato dos alunos com os textos literários. No livro didático analisado, não há, portanto, uma aliança entre teoria e leitura literária que auxilie a formação de um leitor de textos poéticos, principalmente no que se refere à reflexão sobre o gênero "lírico".
\end{abstract}

Palavras-chave: Gêneros literários, letramento lírico, poesia, livros didáticos.

Abstract: This paper presents an analysis of the approach to poetry presented by the textbook Contemporary Portuguese: dialogue, reflection and use (2017), the most selected, and consequently the most distributed textbook, in 2018 National Program for Textbooks and Didactic Materials (PNLD). Aiming to reflect about the place of lyric literacy in Brazilian classrooms, this article discusses the issues that involve the study of literary genres (especially "lyric"), textbooks, and the education of readers. The tentative panorama presented here is not original: schools perpetuate a traditional didactic approach to poetry. Although it is possible to detect a theoretical advance on the subject, this advance is still restricted to the academic field, not reaching schools. Moreover, if the new theoretical assumptions meet the school, what happens then is a "collage" of concepts and systematizations that do not help students' to interact with literary texts. In the textbook here analyzed, therefore, there is no connection between literary theory and literary reading that could help in the education of poetry readers, especially with regard to the understanding of the "lyric" genre.

Keywords: Literary Genres, lyric literacy, poetry, textbooks. 


\section{Contextualização inicial}

Já é consensual a afirmação, desde há algum tempo, de que a formação de leitores literários, no Brasil, passa por diversas dificuldades que bloqueiam a aproximação entre leitores e obras literárias ${ }^{1}$. Mais consensual ainda é a constatação de que a dificuldade dessa formação se acentua amargamente quando se refere ao que podemos chamar de "letramento lírico"2, ou seja, à formação de leitores de poesia. Isso se justifica, de certa forma, pelo fato de o texto poético exigir algumas competências leitoras específicas, devido à sua natureza mais complexa (PINHEIRO, 2018). Entretanto, não se pode restringir essa dificuldade somente à especificidade da poesia, visto ela ser um fenômeno em constante produção e circulação desde as primeiras práticas literárias, fazendo-se necessário refletir sobre os fatores de entrave que dificultam o letramento lírico, principalmente nas salas de aula das escolas brasileiras.

Nesse contexto educacional, o estudo dos livros didáticos é fundamental para a compreensão do processo de letramento literário, tanto pela sua importância na economia editorial brasileira, quanto pelo seu amplo impacto social e cultural, principalmente naquelas situações em que o livro didático é o único meio de contato dos alunos com alguma forma de leitura literária. Segundo Dalvi (2011, p. 186), no Brasil, abordar a formação de leitores, no período contemporâneo, requer, inegavelmente, "considerar que os livros didáticos têm inegável importância na economia da edição e na organização das práticas de leitura levadas a turno pelo processo de escolarização formal".

Levando em consideração o interesse pelas discussões a respeito da poesia, do letramento literário e dos livros didáticos, este trabalho vincula-se ao projeto "A escolarização do gênero lírico no Brasil (séc. XIX e XX): diálogos entre tradição retóricopoética, manuais didáticos e 'cânone literário', desenvolvido no Curso de Mestrado em Letras, na área de Estudos Literários, da Universidade Federal de Santa Maria (UFSM). O objetivo principal desse projeto é sistematizar o processo de escolarização da poesia na região, tendo como material de análise manuais e livros didáticos, e construir um panorama histórico de seu ensino, bem como refletir, principalmente, sobre o lugar do "cânone literário" e as relações estabelecidas por ele com o ensino de Literatura nas escolas. Além disso, direciona-se um olhar crítico para as abordagens teóricas e para a seleção de textos desses materiais, de maneira a perceber se elas contribuem - ou não - para a formação de leitores literários. Tendo em vista essa inserção, este texto objetiva apresentar algumas reflexões e implicações preliminares de tal projeto. Apesar de os resultados por ora atingidos não responderem, diretamente, aos objetivos propostos pelo planejamento principal, eles se configuram como considerações e construções de entremeio que levarão, paulatinamente, ao alcance das metas centrais, pois se configuram como uma justificativa para o olhar histórico proposto pelo projeto. Nesse sentido, acredita-se que a compreensão da configuração atual do lugar da poesia nas escolas seja um ponto de partida primordial para se voltar ao passado e buscar constituir seu processo de escolarização, incluindo seus desenvolvimentos de transformação e/ou manutenção ao longo do tempo.

Assim, este artigo objetiva apresentar um panorama da situação atual concernente à presença de poemas em livros didáticos, baseando-se em uma análise do livro didático de Língua Portuguesa mais escolhido e distribuído a partir do Programa Nacional do Livro Didático (PNLD) de 2018. Para tanto, faz-se

\footnotetext{
1 Alguns autores, por exemplo, que compartilham do mesmo ponto de vista: COSSON, 2018; DALVI, 2013; PERRONEMOISÉS, 2006; PILATI, 2018; PINHEIRO, 2018; RAMALHO, 2014; SEGABINAZI, 2015.

2 Toma-se emprestada a expressão de Ramalho (2014), ao utilizar o termo "letramento lírico" para se referir à competência leitora ainda mais específica em relação ao texto poético, devido a sua natureza mais complexa e a suas peculiaridades. Além disso, observa-se direta relação com o conceito de "letramento literário" (COSSON, 2018).
} 
necessário, também, refletir sobre a definição de "gênero lírico" apresentada por esse livro, uma vez que tal conceituação direciona o olhar para a leitura dos textos literários, dialogando, consequentemente, com a prática de leitura em sala de aula e com a formação de leitores literários.

\subsection{Definições teóricas: poesia ("gênero lírico")}

A questão dos gêneros literários sempre foi um assunto fundamental para a teoria literária, sendo discutida em diferentes momentos e por diversos autores. Embora os gêneros literários estejam consolidados na tradicional tripartição em épico, lírico e dramático, esta vem sofrendo um processo de questionamentos e de revisão teórica. No entanto, são encontradas, de maneira geral, definições limitadas e problemáticas a respeito do gênero lírico, principalmente em materiais destinados a um público de estudantes de ensino médio. Apesar de se estar ciente das limitações teóricas destinadas a esse público, em comparação, por exemplo, a um público acadêmico (estudantes e estudiosos de Letras), é preciso que tal definição esteja a serviço da leitura literária, ou seja, que a própria definição de "gênero lírico" sirva à leitura e à compreensão de textos poéticos por parte dos alunos. Nesse caminho, vale retomar, brevemente, a sistematização teórica a respeito do gênero, apresentando suas dificuldades de definição e de escolarização.

É frequente, em várias fontes de pesquisa, a atribuição da classificação e da sistematização dos ditos "gêneros literários" - lírico, épico e dramático - a Platão e a Aristóteles. Entretanto, como mostram os exaustivos trabalhos de revisão da literatura mais recentes (por exemplo, GENETTE, 1986; BERRIO, 2015), essa atribuição, além de se pautar em uma sistematização a posteriori, torna-se ainda mais problemática quando se está a ler e, sobretudo, a analisar literatura moderna. De acordo com os autores, além dos problemas teóricos e históricos que envolvem tal tripartição, vale pontuar que o (não) lugar do gênero lírico tem sido, desde sempre, uma das principais dificuldades de abordagem.
Ademais, como bem pontua Genette (1986), a definição de lírica como é atualmente conhecida advém de uma leitura romântica e evolucionista dos pressupostos iniciais de Platão e, principalmente, de Aristóteles:

Não se renuncia de modo fácil a projetar no texto fundador da poética clássica uma articulação fundamental da poética 'moderna' - de fato, como é costume, sobretudo romântico. (GENETTE, 1986, p. 20-21).

Segundo o teórico, percebe-se que a divisão fundamental, em Platão e em Aristóteles, era muito bem determinada, pois se referia, categoricamente, aos modos de enunciação dos textos. No entanto:

A divisão romântica e pós-romântica [...] encara o lírico, o épico e o dramático não já como simples modos de enunciação, mas como verdadeiros gêneros, cuja definição comporta já inevitavelmente um elemento temático, por muito vago que seja. (GENETTE, 1986, p. 77).

Tanto para Genette (1986, p. 77), quanto para Berrio (2015, p. 20), tem-se em Friedrich Hegel o exemplo mais evidente desse posicionamento romântico frente aos gêneros literários. A partir disso, ocorre a união da já consolidada tripartição dos gêneros literários a critérios relacionados à focalização simbólica: o pensamento hegeliano tornase conhecido como uma dialética linear, sobretudo evolucionista, entre a subjetividade lírica e a objetividade épica, cujo ponto de encontro, consequentemente, está sintetizado na esfera dramática (subjetiva e objetiva). Essa associação da lírica à subjetividade é a encontrada, até hoje, nos principais manuais teóricos e didáticos que discutem os gêneros literários. Por isso, é muito comum encontrar o gênero lírico associado ao "mundo interior" do poeta, à sua interioridade, à subjetividade de seus sentimentos.

$\mathrm{Na}$ escola, os problemas que decorrem dessa confusão teórica estão, principalmente, nos embaraços didáticos no momento de ler certos poemas que "fogem" aos exemplos-padrão da tripartição tradicionalmente arraigada na didática escolar. Nem todo poema é subjetivo. Nem todo 
poema é sentimental. Há poemas narrativos. Há poemas dramáticos. Como trabalhar com a particularidade de cada leitura literária a partir da definição fechada apresentada pela quase totalidade dos livros didáticos?

Como "saídas" metodológicas, tem-se, a título de exemplo, as propostas de Frye (2014), Genette (1986) e Berrio (2015), que, apesar de bastante complexas e imbricadas na teoria literária, poderiam ser adaptadas ao contexto educacional a partir dos conceitos de "modos" e "gêneros" (cf. GENETTE, 1986). Apesar de cada teórico utilizar a nomenclatura que lhe é característica, o importante de tais proposições é o fato de todas levarem em consideração a distinção entre duas categorias que se encontram em níveis de análise distintos, ou seja, um nível teórico e um nível histórico. O "modo" seria uma categoria linguística, pragmática, referente às formas básicas de comunicação/enunciação, e, por isso, mais abstrata; já o "gênero" seria uma categoria literária, a própria materialidade do texto, configurada como uma estrutura de composição histórica e, por isso mesmo, mutável (GENETTE, 1986).

Apesar de a proposta figurar em âmbito acadêmico, essa abordagem ainda não ganhou espaço na escola. É evidente que uma sistematização tão complexa e abstrata, teórica e historicamente, dificulta a escolarização e, consequentemente, a abordagem didática de sua metodologia nas escolas. Entretanto, acredita-se que já se passou do momento de propor alternativas que, a partir de mudanças em currículos e em livros didáticos e de projetos didático-pedagógicos, possam dar conta da leitura dos mais diversos textos poéticos disponíveis no mundo atual. "Dar conta", aqui, diz respeito ao contato do aluno com o texto poético: o importante de uma sistematização é que ela esteja a serviço da leitura e da compreensão dos textos, indo ao encontro de uma formação integral de letramento literário dos alunos.

\subsection{Definições teóricas: "Livro didático"}

Já em relação ao conceito de "livro didático", é possível afirmar que também se caminha em um percurso bastante amplo, controverso e de inúmeras possibilidades analíticas. Essa amplitude e/ou falta de definição específica inicia-se pela própria denominação "livro didático", que, no decorrer dos anos, foi sendo referida de diversas formas e com diversos objetivos, de acordo com o apresentado por Choppin (2009). Circe Maria Fernandes Bittencourt apresenta, em seu texto "Em foco: história, produção e memória do livro didático" (2004), a amplitude das discussões sobre esse objeto, que engloba tanto o interior da escola, entre alunos, educadores e familiares, quanto 0 exterior, como eventos acadêmicos, artigos de jornais, autores, editores, autoridades políticas, intelectuais de diversas procedências. Além disso, a autora também ressalta a importância econômica e mercadológica da produção dos livros, enfatizando a figuração do Estado como agente de controle e consumidor da produção de livros escolares.

Indo ao encontro do apresentado por Choppin (2004), Bittencourt (2004, p. 471) também apresenta a complexidade do livro didático, destacando que é "praticamente impossível defini-lo". Objeto de múltiplas facetas, ele é pesquisado na qualidade de: produto cultural, mercadoria ligada ao mundo editorial e dentro da lógica de mercado capitalista, suporte de conhecimentos e de métodos de ensino das diversas disciplinas e matérias escolares, e veículo de valores, ideológicos ou culturais (BITTENCOURT, 2004, p. 471).

Como se pode perceber, então, o campo de estudos que se dedica aos livros didáticos (ou livros escolares) é bastante amplo e exige um olhar cuidadoso para se conseguir perceber e analisar todas as imbricações sociais, políticas, econômicas, culturais e educacionais que permeiam o objeto. Apesar de ressaltar a importância de uma compreensão mais englobante a respeito desse objeto, também se faz necessário pontuar que, devido aos objetivos e às limitações de cada estudo, é 
sempre preciso delimitar e recortar o olhar direcionado a cada pesquisa. Por isso, este trabalho pensa o livro didático, sobretudo, como uma construção simbólica que carrega em si pressupostos e abordagens históricas pertencentes a uma tradição escolar anterior e, por isso mesmo, subjacente ao próprio objeto.

Dadas as problematizações ora apresentadas, torna-se evidente a necessidade de compreender, histórica e teoricamente, os fatores que dizem respeito não só ao ensino de poesia na escola, mas, principalmente, ao lugar desse ensino nos livros didáticos. Dessa forma, pensar o lugar da poesia no livro Português contemporâneo: diálogo, reflexão e uso é uma forma de refletir tanto sobre a formação de leitores de poesia no presente quanto uma abertura para investigar e reconstituir a trajetória desse ensino, - que será desenvolvido a partir de um olhar comparativo em relação à configuração atual.

\section{Uma análise da situação atual: PNLD 2018 - Português contemporâneo: diálogo, reflexão e uso}

É importante retomar algumas informações básicas referentes ao PNLD antes de seguir a análise aqui proposta, tendo em vista uma compreensão mais geral da configuração e da importância desse programa para as escolas públicas de educação básica. Com o Decreto n.ㅇ 91.542, de 19 de agosto de 1985, que "institui o Programa Nacional do Livro Didático, dispõe sobre sua execução e dá outras providências", iniciou-se uma nova fase em relação à presença e ao processo de distribuição de livros didáticos no Brasil.

Os principais pontos desse decreto dizem respeito à distribuição de livros escolares a todos os estudantes matriculados nas escolas públicas de $1^{\circ}$ Grau e à participação dos professores na escolha desses livros, pois eles passam a fazer parte do processo de análise e indicação dos livros a serem adotados. Além disso, também se reitera a importância da reutilização dos livros, que, com o tempo, formariam bancos de livros didáticos, estimulando-se seu uso e conservação.

Atualmente, o PNLD objetiva adquirir e distribuir livros didáticos, por meio de seu funcionamento, "aos alunos da educação infantil, dos anos iniciais e finais do ensino fundamental e do ensino médio" (FNDE, 2019, não paginado). Portanto, há, anualmente, ações específicas que visam a atender determinados níveis de ensino, a fim de prover de materiais didáticos todos os alunos de todas as modalidades de ensino beneficiadas pelo programa ao longo do tempo.

Em 2018, o PNLD direcionou seu atendimento a todos os alunos das escolas públicas brasileiras matriculados no ensino médio. Assim, foram selecionados diversos livros didáticos, disponibilizados para consulta aos professores, para que integrassem a lista de livros a serem adquiridos e distribuídos nas escolas. Especificamente em relação aos de Língua Portuguesa selecionados pelo PNLD 2018, 11 foram as coleções (volumes 1, 2 e 3) selecionadas. Para a análise aqui proposta, o foco recairá nos exemplares referentes ao primeiro ano do ensino médio, ou seja, aos primeiros volumes das coleções, pois é nessa etapa que, comum e tradicionalmente, são apresentados os gêneros literários, capítulo ou seção em que se discute a configuração do "gênero lírico" e se define o que seria um "poema" ou "poesia".

Desses 11 livros selecionados para análise e escolha pelos professores, segundo dados apresentados no site do $\mathrm{FNDE}^{3}$, um deles se sobressaiu, sendo adquirido de maneira bastante considerável: o livro Português contemporâneo: diálogo, reflexão e uso, de autoria de William Cereja, Carolina Dias Vianna e Christiane Damien e publicado pela editora Saraiva (2017), em sua primeira edição. Dos 3.140 .156 exemplares adquiridos de Língua Portuguesa (Volume 1), referentes ao primeiro ano do ensino médio,

\footnotetext{
${ }^{3}$ Ver tabela completa dos livros adquiridos a partir do download do arquivo "PNLD 2019 - Valores de aquisição por título", disponível em http://www.fnde.gov.br/programas/programas-dolivro/pnld/dados-estatisticos.
} 
1.254.128 dizem respeito ao referido livro, o que representa um percentual de 39,95\% somente para essa obra. Os 60,06\% restantes dividem-se em aquisições de outros dez diferentes títulos, sendo que o segundo mais adquirido somente atinge 15,04 \% do total de livros distribuídos.

Tendo em vista as estatísticas apresentadas, é possível inferir que o livro que mais circula pelas salas de aula das turmas de primeiros anos do ensino médio, nas escolas públicas brasileiras, é o livro didático Português contemporâneo: diálogo, reflexão e uso, que será o objeto de análise deste trabalho. Para dar prosseguimento às reflexões, o primeiro foco analítico específico irá se concentrar na definição de "gênero lírico" apresentada pelo livro, para que seja possível verificar o método de abordagem teórica desse gênero literário. Posteriormente, serão discutidos alguns dados referentes à proposição de leitura de poemas pelo livro, apresentando-se a quantidade de textos disponibilizados para leitura e a forma como essa leitura é, metodologicamente, apresentada aos alunos.

\subsection{Análise inicial: organização didático-metodológica}

Antes de se iniciar a análise específica desta seção, faz-se relevante apresentar, brevemente, uma contextualização temática e organizacional a respeito do sumário do livro em análise. Como muitos outros, - livro é organizado em quatro unidades bastante amplas que englobam capítulos subdivididos em três "seções" específicas: "Literatura", "Língua e linguagem" e "Produção de texto", o que é bastante tradicional quando se trata de livros didáticos para 0 ensino médio. Como se pode perceber, apesar de o livro abordar, em uma única unidade, as três "esferas" principais do ensino das linguagens na escola, há uma evidente sistematização entre conteúdos que seriam mais típicos da literatura e aqueles mais característicos das aulas de língua portuguesa, o que é um reflexo direto da organização curricular por disciplinas adotada nesse nível de ensino.

Especificamente em relação à literatura, há alguns tópicos direcionados, apresentados na seguinte ordem: "O que é literatura?", "O Trovadorismo", "Gil Vicente", "O Classicismo", "Camões", "Literatura de informação", "O Barroco", "Gregório de Matos", "Pe. Antônio Vieira", "O Arcadismo", "Cláudio Manuel da Costa e Tomás Antônio Gonzaga" e "Basílio da Gama". Conforme se observa, o livro segue uma prática editorial bastante comum em relação aos livros didáticos da disciplina: apresenta uma discussão inicial a respeito da literatura, de seus conceitos, funções e organização didática, para, posteriormente, seguir por um viés historiográfico e representativo dos principais poetas e escritores de cada período.

Em relação à distribuição quanto ao número de páginas reservadas a cada uma das seções, a Tabela é bastante ilustrativa:

Tabela - Número de páginas por conteúdos

\begin{tabular}{c|c}
\multicolumn{1}{c|}{ Conteúdo } & $\begin{array}{c}N^{o} \text { de } \\
\text { páginas }\end{array}$ \\
\hline Elementos Pré-textuais & $\mathbf{1 1}$ \\
\hline - Capa e contracapa & 2 \\
\hline - Apresentação & 1 \\
\hline - Conheça seu livro & 4 \\
\hline - Sumário & 4 \\
\hline Elementos Textuais & $\mathbf{3 1 8}$ \\
\hline - Literatura & 100 \\
\hline - Língua e Linguagem & 95 \\
\hline - Produção de texto & 91 \\
\hline - Outros (Enem + Projeto + & 32 \\
\hline Unidades) & $\mathbf{7}$ \\
\hline Elementos Pós-textuais & 6 \\
\hline - Apêndice & 1 \\
\hline - Bibliografia & $\mathbf{3 3 6}$ \\
\hline
\end{tabular}

Fonte: elaborado pelos autores.

A partir dos dados apresentados na Tabela, o que se destaca, positivamente, é o fato de a seção de "Literatura" apresentar um maior número de páginas em comparação às outras duas seções ("Língua e Linguagem" e "Produção de texto") que compõem a obra. Essa configuração é ainda reiterada pelo fato de que as discussões sobre literatura também aparecem, mesmo que de forma mais distribuída e não tanto sistematizada, nas seções "Outros", pois há a presença de textos literários, por exemplo, nas páginas destinadas às questões de Enem e vestibulares. 
Dessa forma, das 336 páginas totais que compõem o livro didático em análise, a seção destinada aos estudos literários ocupa um percentual de aproximadamente 29,8 \%. Além disso, como será tratado de forma mais pontual no decorrer deste artigo, é interessante observar que esse percentual restringe-se somente ao conteúdo específico da área, mas que, no decorrer de todas as outras seções, há a constante presença de textos literários (quase sempre trechos), principalmente para exemplificação de conteúdos teóricos e como textos de apoio a atividades a serem realizadas pelos alunos. Desses dados, o que se pode concluir é que as discussões a respeito da literatura são bastante frequentes nas seções do livro, restando, agora, analisá-las quanto à qualidade dessa presença.

\subsection{Conceito de "gêneros literários"}

De antemão, é importante observar que, em rápida comparação aos outros livros selecionados no PNLD de 2018, o livro didático aqui analisado é o que, dentro do possível, melhor apresenta a problemática de definição dos gêneros literários. Embora bastante generalista e sem comprovação direta neste texto ${ }^{4}$, essa constatação torna-se evidente pelo fato de, como será evidenciado a seguir, as escolhas linguísticas dos textos presentes no livro referenciarem algumas discussões de forma cautelosa e apresentarem ressalvas quanto a definições estanques e a-históricas. Porém, apesar dessa maior lucidez em relação ao assunto, ainda há algumas questões que se colocam de maneira arriscada, como a confusão no uso dos termos e a falta de uma definição singular para os assuntos tratados, conforme se poderá verificar nas averiguações apresentadas.

Como é possível imaginar por já se tratar de uma prática comum, a discussão a respeito dos gêneros literários e/ou da distinção entre as diversas manifestações literárias é apresentada nas primeiras reflexões acerca da literatura. Entretanto, o livro em análise inova e surpreende ao apresentar a seguinte divisão, em seu primeiro capítulo:

Figura 1 - Capítulo 1 (Sumário)

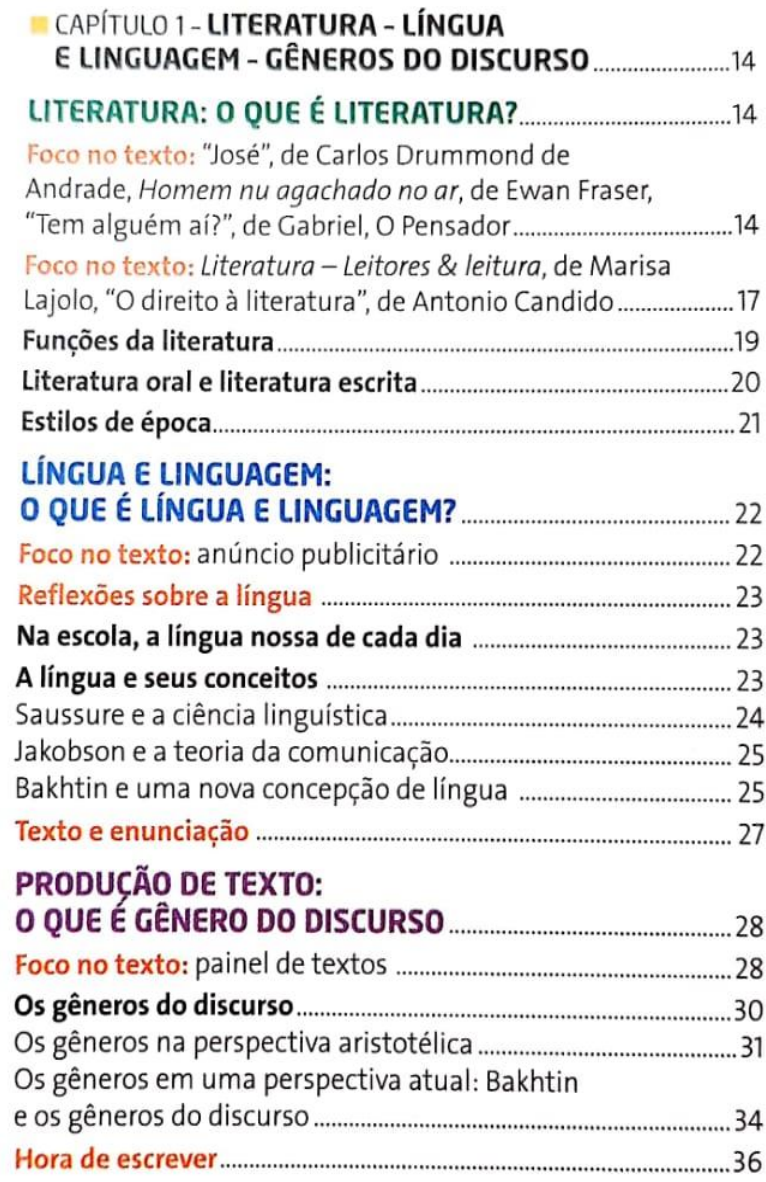

Fonte: (CEREJA; VIANNA; DAMIEN, 2016, p. 8).

De acordo com a Figura 1, a discussão a respeito dos gêneros literários não é apresentada na seção específica sobre literatura, que se restringe a refletir sobre o conceito de literatura, sobre suas funções, sobre seu caráter oral e escrito e sobre os estilos de época, pois não há menção à conceituação dos gêneros literários. Entretanto, na seção específica sobre produção de texto, apresenta-se o conceito de "gêneros do discurso", e aqui é preciso deter-se de maneira mais detalhada. Quanto à definição de gêneros do discurso, assim apresenta o livro didático:

\footnotetext{
4 Um artigo que analisa as 11 obras selecionadas no PNLD está em fase de finalização e submissão, por isso as constatações preliminares ora apresentadas.
} 
$\mathrm{Na}$ atividade anterior, você observou que determinadas características (estrutura, estilo, finalidades, autores, interlocutores, entre outras) são comuns a certos textos e aparecem de forma recorrente, o que torna possível classificar um texto novo com base em outros já conhecidos.

Essas semelhanças, menos ou mais recorrentes, compõem o que se chama de gêneros do discurso.

Como vimos na seção Língua e linguagem, há muitos e muitos séculos a linguagem e os textos têm sido foco de estudo. O conceito de gênero, da mesma forma, não é novo, embora no passado o foco dos estudos nessa área fossem os gêneros literários. (CEREJA; VIANNA; DAMIEN, 2016, p. 31, grifos dos autores).

O que essa primeira definição expõe é uma abordagem discursiva bastante recente da teoria da linguagem, ancorada, principalmente, nos pressupostos de Mikhail Bakhtin. O que chama atenção é a parte final da citação, que contrapõe a definição de gênero apresentada a uma definição mais antiga que se insere com foco nos gêneros literários. Até aqui, pode haver uma confusão entre essas diferentes denominações, pois se dá a entender que os gêneros literários eram estudados no passado, já que, atualmente, deram lugar aos estudos dos gêneros do discurso. Porém, essa leitura ainda se encontra um pouco confusa, sendo necessário ver o que, na sequência, o livro apresenta:
O texto apresentado na Figura 2 apresenta, sumariamente, as contribuições de Platão e Aristóteles aos estudos dos gêneros literários, como discutido em seção anterior deste artigo. É importante destacar, positivamente, a forma como essa contribuição foi apresentada, pois não atribui diretamente - aos antigos gregos a sistematização dos gêneros em dramático, lírico e épico, um erro bastante comum em outros livros didáticos. Além disso, também se refere aos "meios utilizados para realizar essa sistematização", o que, teoricamente, está muito bem formulado, conforme apresentado nas discussões de Genette (1986). Ou seja, o livro apresenta aos alunos de onde surgiu a tríade inicial e o que, tradicionalmente, foi-se elaborando a partir dela. Para finalizar, o livro também aborda o problema atual dessa classificação, devido ao surgimento de novos textos e à renovação do fazer literário, insistindo que, apesar dessa dificuldade, é ainda importante conhecê-la.

Figura 2 - Os gêneros na perspectiva aristotélica

\section{Os gêneros na perspectiva aristotélica}

Platão e Aristóteles, na Grécia antiga (século III a.C.), já refletiam sobre as características dos textos literários e as funções que esses textos desempenhavam socialmente e, entre elas, destacavam o papel da literatura como imitação da realidade humana.

Da concepção clássica desses pensadores, surgiu uma divisão dos textos literários em três gêneros básicos, que imitariam a vida, diferenciando-se entre si pelos meios utilizados para realizar essa imitação. São eles os gêneros dramático, lírico e épico.

Atualmente, essa classificação é questionada por estudiosos, pois, com o passar do tempo, novos gêneros literários surgiram e gêneros literários antigos se renovaram. Vale a pena, no entanto, conhecê-la, pois ela serviu de base para os estudos posteriores sobre os gêneros literários.

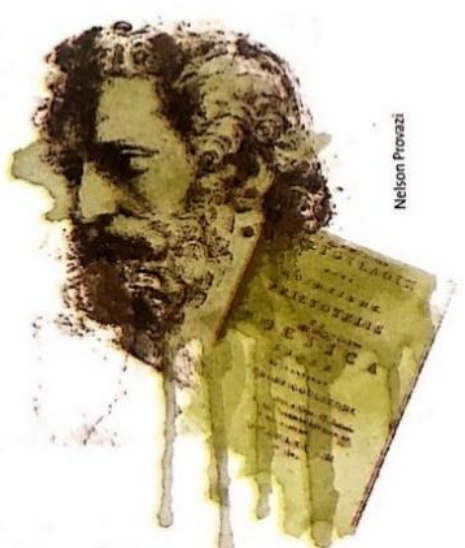

Fonte: (CEREJA; VIANNA; DAMIEN, 2016, p. 31). 
No entanto, vale perceber que somente conhecer a tríade dos gêneros literários não é suficiente para o contato com os diversos textos literários, sendo importante, portanto, perceber como essa teorização será retomada na sequência do livro, principalmente quando do contato dos alunos com a leitura literária. Quanto ao "gênero lírico", tem-se:

Figura 3 - Conceito de gênero lírico

\section{Gênero lírico}

Nas composiçoes do gênero lirico, não há personagens e o poeta se expressa na voz de um eu lirico que fala de suas emoçōes e impressōes sobre o mundo. Em geral, essas composições exploram efeitos sonoros, tais como repetição, ritmo e a musicalidade das palavras.

No poema lirico abaixo, por exemplo, a repetição das palavras que e como no inicio de versos contribui para dar ritmo ao poema, enquanto a repetição do som $/ \mathrm{s} /$ confere musicalidade ao texto.

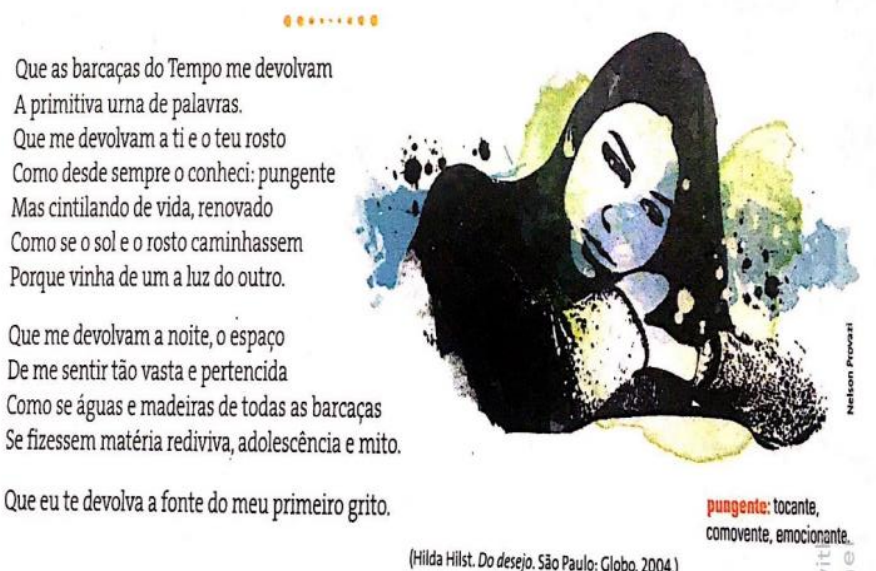

Fonte: (CEREJA; VIANNA; DAMIEN, 2016, p. 32).

De maneira superficial, o primeiro ponto a se ressaltar é a sucinta apresentação do gênero, sem muito aprofundamento conceitual, e que parece atribuir - erroneamente - a Aristóteles as caracterizações apresentadas, pois os subtítulos de "gênero dramático", "gênero lírico" e "gênero épico" estão apresentados sob o título maior de "Os gêneros na perspectiva aristotélica" (ver Figura 2). Além disso, a afirmação de que "não há personagens" também se torna confusa e bastante ampla, pois não se explica, de maneira pontual, o que se entende por não haver personagens. Para os alunos, o conceito de "personagem" já é evidente? São questões que podem se tornar bastante delicadas quando do contato dos alunos com poemas narrativos, por exemplo, que fazem uso, de certa forma, de "personagens" em ação. Ademais, vale observar a influência romântica quanto ao trato de o eu lírico falar de suas emoções, associando-se, portanto, o gênero lírico à subjetividade do eu lírico apresentado.

$\mathrm{Na}$ sequência dessas definições, há um exercício que solicita ao aluno classificar alguns textos "conforme a divisão dos gêneros literários concebida por Platão e Aristóteles" (CEREJA; VIANNA; DAMIEN, 2016, p. 33). Veja-se que, agora, já se atribui aos gregos a formulação da divisão em três gêneros literários. Como exemplo, tem-se um trecho de Odisseia, de Homero, e um poema de Florbela Espanca, de temática amorosa. Para a atividade proposta, os exemplos são evidentes e de simples resolução... Aconteceria o mesmo se os textos selecionados exigissem maior detalhamento, como é o caso da literatura moderna?

$\mathrm{Na}$ sequência, há um tópico intitulado "Os gêneros em uma perspectiva atual: Bakhtin e os gêneros do discurso" (CEREJA; VIANNA; DAMIEN, 2016, p. 34). Percebe-se, novamente, o contraste entre uma perspectiva antiga (dos gêneros literários) e uma perspectiva atual (dos gêneros do discurso). No decorrer da apresentação dos pressupostos bakhtinianos, encontra-se: "Tendo em vista a importância que os textos têm em nossa vida, a opção pelo estudo exclusivo do texto literário, como faziam os gregos, não mais se justifica" (CEREJA; VIANNA; DAMIEN, 2016, p. 34). É possível perceber um tom depreciativo em relação ao trabalho empreendido por Platão e Aristóteles, o que é bastante problemático, pois não se pode esquecer que, à época desses gregos, a noção de "literatura" como a entendemos hoje ainda não existia, e o número de textos e a diversidade destes era muito mais limitada. Ademais, os autores desconsideram ainda os gêneros retóricos, cujo estudo foi fundamental para o desenvolvimento posterior das teorias de gênero.

Ao tratar sobre a esfera de circulação dos gêneros, o livro apresenta, na continuação, a seguinte afirmação: "Na esfera literária, há gêneros como poemas, contos, crônicas, romances, etc." (CEREJA; VIANNA; DAMIEN, 2016, p. 36). Tem-se, com isso, a distinção entre a antiga tripartição dos gêneros em lírico, épico e dramático e o atual sistema de gêneros 
literários, que engloba, sob uma perspectiva discursiva e de maneira mais ampla, as diversas manifestações consideradas hoje literárias. Apesar de ser possível assim interpretar tal afirmação, ela não está explícita no livro, sendo necessária uma mediação do professor. É interessante o exemplo apresentado pelo livro na sequência:
Nesse caminho, é na confusão teórica entre as duas perspectivas que recai a problemática de abordagem didática dos gêneros presente no livro em análise: no momento da leitura literária, os pressupostos teóricos precisam auxiliar o processo de leitura do aluno, proporcionando a ele características básicas de a proximação aos textos. Resta analisar,

Figura 4 - Exemplo

É possivel, ainda, que um texto mescle caracteristicas de dois ou mais gêneros em sua composição, seja para chamar a atenção de seus leitores, seja para fazer alguma brincadeira, entre outros motivos. É o caso do poema "Receita", de José Saramago, reproduzido abaixo. Nele, o autor utilizou uma forma simplificada de receita (cita quantidades e ingredientes para uma suposta "massa" e explica como proceder) para produzir um poema que trata da escrita de poemas.

\section{Receita}

Tome-se um poeta não cansado, Uma nuvem de sonho e uma flor, Três gotas de tristeza, um tom dourado, Uma vela sangrando de pavor. Quando a massa já ferve e se retorce Deite-se a luz de um corpo de mulher, Duma pitada de morte se reforce, Que um amor de poeta assim requer.

(Os poemas possiveis. Alfragide, Portugal: Editorial Caminhos, 1997. p. 125.)

s.

Fonte: (CEREJA; VIANNA; DAMIEN, 2016, p. 64.)

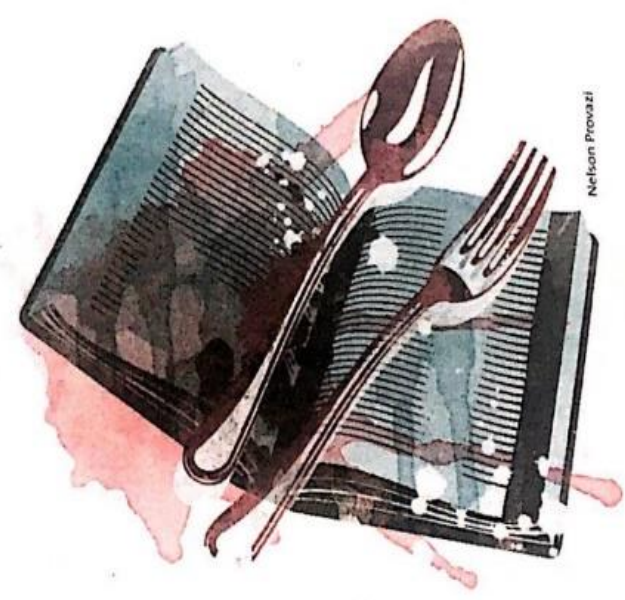

então, como o livro, no decorrer de seus capítulos, retomará essa aproximação. Aqui, um novo problema surge: a discussão a respeito da classificação dos gêneros não é mais abordada, não solicitando ao aluno uma reflexão sobre os textos literários lidos. No decorrer do livro didático, vários textos são apresentados a partir das definições: cantiga de amor, cantiga de amigo, poema lírico, poema épico, soneto, etc., mas não se retoma a conceituação e as características de cada um desses gêneros. Surge, então, a seguinte indagação: a sistematização apresentada no primeiro capítulo serviu à formação de um leitor mais competente frente aos diferentes textos literários? 
2.3 Presença de poemas para leitura

Para analisar a presença de poemas no livro em análise, foram adotados dois critérios específicos: numérico e funcional. $O$ primeiro refere-se ao número de poemas e/ou trechos de poemas apresentados para leitura, enquanto o segundo critério objetiva responder as perguntas: "para quê?" e "onde?", visto ser frequente 0 fato de se encontrarem trechos (versos) de poemas somente como exemplificação de certo conteúdo ou como parte de enunciados de atividades.

Nas seções específicas sobre literatura, quanto à presença de poemas, encontram-se 26 poemas "líricos" (em oposição aos poemas épicos, pois há 2 trechos de Os Lusíadas e 1 trecho de O Uraguai), 3 canções, 1 cantiga oral e 1 cordel. Nas outras seções e partes que compõem a obra, encontram-se 21 poemas "líricos", 2 poemas épicos, 2 canções e 1 "texto poético em prosa". Caso se somem todas essas ocorrências que podem suscitar a discussão sobre o "gênero lírico" e sobre as relações entre modos distintos de apresentação dos textos, tem-se um número significativo de leituras a serem realizadas pelos alunos.

No entanto, volta-se ao problema qualitativo: essas leituras retomam os "conteúdos" teóricos apresentados anteriormente? Auxiliam a compreensão do fazer poético e possibilitam a reflexão sobre mudanças e permanências desse fazer? O que se percebe, infelizmente, é que elas somente servem à discussão momentânea proposta pela seção do livro, não ocorrendo uma continuidade quanto ao processo de formação de repertório, tanto teórico, quanto literário.

A título de exemplo, em uma seção de "Língua e Linguagem", para discutir as figuras de linguagem, são apresentados 10 conjuntos de versos (trechos de poemas) como exemplos às figuras citadas. Não há um olhar que direcione a presença dessas figuras à configuração textual do gênero, por exemplo, que pudesse contribuir para uma reflexão sobre o papel dessas figuras de linguagem na totalidade da leitura do poema. Essa falta de imbricação entre teoria e leitura, entre apresentação de pressupostos teóricos e falta de continuidade, é um dos grandes problemas na formação de leitores literários, como já apontava Todorov (2009).

O que se pode concluir, como citou Pinheiro (2018), fazendo referência ao trabalho de Alves (2012) ao analisar livros didáticos do ensino fundamental publicados entre o final do século $X X$ e início do XXI, é que, apesar de haver uma presença considerável de poemas e de poetas contemporâneos, a abordagem desses textos não ultrapassa o nível formal e/ou temático desses poemas. Dessa forma, parece haver um distanciamento entre os avanços teóricos a nível superior e a escolarização dessa mesma teoria. $O$ livro didático tende a funcionar como uma colagem de visões teóricas somente a título de exposição de "conteúdos", não existindo um direcionamento palatável para a leitura de textos literários (principalmente os "líricos") e, consequentemente, para a formação de leitores de poesia.

\section{Reflexões provisórias}

Tendo em vista a análise empreendida quanto à abordagem direcionada à leitura de poesia no livro didático Português contemporâneo: diálogo, reflexão e uso e as discussões a partir dela apresentadas, fazse relevante refletir sobre a importância da compreensão do panorama da situação atual do ensino de poesia nas salas de aula. Compreender os problemas e apontar os equívocos ou as confusões teóricas atualmente encontradas nos materiais didáticos é um ponto de partida para dois olhares distintos frente ao mesmo objeto: um de retorno ao passado e de reconstituição dos processos de escolarização que permeiam o ensino da poesia; e outro de busca por soluções futuras que possam, levando-se em consideração o passado e o presente, (res)significar a leitura literária de poesia nas escolas.

Nesse caminho, em relação à definição teórica de "gêneros literários" apresentada pelo livro, recorte 
de análise deste texto ${ }^{5}$, é importante destacar os problemas de atribuição e de sistematização que, historicamente, foram sendo relacionados à tradicional tripartição entre épico, lírico e dramático e que se encontram presentes no livro didático. Especificamente quanto ao "gênero lírico", a abordagem que permanece é, como apontado nas análises, fruto de uma visão romântica e evolucionista dos gêneros, que acabou atribuindo ao lírico as características que o relacionam à subjetividade e ao mundo interior do eu-lírico.

Além disso, o principal problema dessas concepções teóricas evidencia-se quando os alunos se deparam com textos que fogem aos padrões estéticos tradicionais, ou seja, com a maioria dos textos modernos com os quais se tem contato diariamente. Mesmo que o livro didático não promova sempre a discussão desses textos, eles aparecerão, em diversos momentos, para os alunos. Resta a pergunta: como se dará o contato dos alunos com esse tipo de texto? Os conhecimentos teóricos (que já eram confusos, frutos de um agrupamento de visões teóricas) auxiliarão o primeiro contato do aluno para que ele consiga perceber as configurações e as características principais do texto a ser lido?

Dessa forma, apesar de o livro apresentar um número bastante significativo de poemas para análise, essas reflexões quanto à elasticidade de caracterização do gênero não aparecem no momento de leitura dos textos literários. É possível afirmar que os pressupostos teóricos apresentados servem somente como subsídios para a realização das atividades propostas na sequência, as quais já são selecionadas tendo em vista a realização direta das questões. Ou seja, a abordagem dos pressupostos teóricos não auxilia a formação de leitores literários de poesia, pois não capacita os alunos para um olhar reflexivo frente aos textos poéticos a serem lidos e analisados.

\footnotetext{
${ }^{5}$ Vale sublinhar que as considerações aqui apresentadas são justificadas pelo recorte selecionado neste artigo, não compreendendo, de forma alguma, a complexidade do material como um todo. Há muitos outros recortes possíveis a serem analisados na obra, porém exigem outros direcionamentos e uma abordagem específica atrelada a outros objetivos.
}

O que se pode concluir, então, é que, no complexo universo de definição do gênero lírico e dos livros didáticos, o lugar do letramento literário e, principalmente, do letramento lírico, ainda se encontra muito apagado frente às abordagens tradicionais que visam a "ensinar um conteúdo" e a "realizar exercícios". Além de todos os problemas teóricos que envolvem os conceitos estudados, há ainda muita dificuldade para romper barreiras com uma tradição há muito consolidada nas salas de aula. Ademais, as revisões teóricas que, desde há algum tempo, já vêm sendo realizadas na academia não conseguem chegar até a escola (cf. PINHEIRO, 2018, p. 126), ou, se chegam, como é o caso da visão bakhtiniana dos gêneros do discurso, por exemplo, acabam se misturando às visões mais antigas e já apresentadas pelos livros, gerando uma "colagem" de pressupostos teóricos que mais confundem os alunos do que os capacitam e os formam como leitores literários autônomos frente a qualquer texto poético.

\section{Referências}

BERRIO, Antonio García; CALVO, Javier Huerta. Los géneros literarios: sistema e historia. 6. ed. Madrid: Cátedra, 2015. 274 p.

BITTENCOURT, Circe Maria Fernandes. Em foco: história, produção e memória do livro didático. Educação e Pesquisa, São Paulo, v. 30, n. 3, p. 471-473, set./dez. 2004.

BRASIL. Decreto n. 9 91.542, de 19 de agosto de 1985. Institui o Programa Nacional do Livro Didático, dispõe sobre sua execução e dá outras providências. Diário Oficial da União, seção 1, p. 12178, 20 ago. 1985. Disponível em: https://www2.camara.leg.br/legin/fed/decret/19801987/decreto-91542-19-agosto-1985-441959publicacaooriginal-1-pe.html. Acesso em: 9 jul. 2019.

CEREJA, William; VIANNA, Carolina Dias; DAMIEN, Christiane. Português contemporâneo: diálogo, reflexão e uso. 1. ed. São Paulo: Saraiva, 2017. (Vol. 1). 336 p.

CHOPPIN, Alain. História dos livros e das edições didáticas: sobre o estado da arte. Tradução de Maria Adriana C. Cappello. Educação e Pesquisa, São Paulo, v. 30, n. 3, p. 549-566, set./dez. 2004. 
CHOPPIN, Alain. O manual escolar: uma falsa evidência histórica. Tradução de Maria Helena C. Bastos. História da Educação, ASPHE/FaE/UFPel, Pelotas, v. 13, n. 27, p. 9-75, jan./abr. 2009.

COSSON, Rildo. Letramento literário: teoria e prática. 2. Ed. São Paulo: Contexto, 2018. 139 p.

DALVI, Maria Amélia. A poesia contemporânea em livros didáticos e a formação de leitores escolarizados: a trapaça institucionalizada. Revista Contexto, Vitória, n. 20, jul./dez. 2011, p. 183-217.

DALVI, Maria Amélia. Literatura na escola: propostas didático-metodológicas. In: DALVI, Maria Amélia; REZENDE, Neide Luzia de; JOVER-FALEIROS, Rita. (Orgs.). Leitura de literatura na escola. São Paulo: Parábola, 2013. 165 p. p. 67-97.

FNDE. Dados estatísticos. Programas do livro. Brasília, 2019. Disponível em: http://www.fnde.gov.br/programas/programas-dolivro/pnld/dados-estatisticos. Acesso em: 8 jun. 2019.

FRYE, Northrop. Anatomia da crítica: quatro ensaios. Tradução de Marcus De Martini. São Paulo: É Realizações, 2014. 584 p.

GENETTE, Gérard. Introdução ao Arquitexto. Tradução de Cabral Martins. Organização de Maria Alzira Seixo. Lisboa: Vega, 1986. (Coleção Vega Universidade). 109 p.
PERRONE-MOISÉS, L. Literatura para todos. Literatura e Sociedade, São Paulo, v. 11, n. 9, p. 16-29, 2006.

PILATI, Alexandre. Poesia na sala de aula: subsídios para pensar o lugar e a função da literatura em ambientes de ensino. 3. ed. Campinas: Pontes Editores, 2018. 119 p.

PINHEIRO, Hélder. Poesia na sala de aula. 1. ed. São Paulo: Parábola, 2018. 152 p.

RAMALHO, Christina Bielinski. A poesia é o mundo sendo: o poema na sala de aula. Revista da Anpoll, Florianópolis, n. 36, p. 330-370, jan./jun. 2014.

SEGABINAZI, Daniela Maria. Literatura nas aulas de língua portuguesa? Onde está o texto literário no ensino fundamental e médio? In: FRANCELINO, Pedro Farias; SEGABINAZI, Daniela Maria (Orgs.). Língua, literatura e ensino: concepções, diálogos e convergências. João Pessoa: Editora da UFPB, 2015. 235 p. p. 13-40.

TODOROV, T. A literatura em perigo. Tradução de Caio Meira. 2. ed. Rio de Janeiro: DIFEL, 2009. 96 p.

\section{COMO CITAR ESSE ARTIGO}

DAMBROZIO GUERRA, Caroline; DE MARTINI, Marcus. A leitura de poesia e sua escolarização: os livros didáticos e a formação de leitores. Signo, Santa Cruz do Sul, v. 45, n. 82, jan. 2020. ISSN $1982-2014$. Disponível em: <https://online.unisc.br/seer/index.php/signo/article/view/14331>. Acesso em: doi:https://doi.org/10.17058/signo.v45i82.14331. 